\title{
Field investigation of nutrient pulse mixing in an in situ biostimulation experiment
}

\author{
J. F. Devlin and J. F. Barker \\ Department of Earth Sciences, University of Waterloo, Waterloo, Ontario, Canada
}

\begin{abstract}
A permeable wall was installed in a shallow, uncontaminated portion of the Borden aquifer, and periodically flushed with a solution of potassium acetate. The acetate pulses were injected at intervals of 5-7 weeks and were observed to merge within 5-10 m of the injection wall. The chief mechanism for the merging of these pulses was longitudinal dispersion. Geochemical changes in the aquifer, manifested as the development of a sustained reducing environment, indicated that the dispersive mixing occurred at the scale of the microorganisms and was not merely an artifact of the sampling method. This work indicates that large-period pulsed injections of a substrate solution might be useful in bioremediation programs where the promotion of injected and ambient water mixing is desirable. It is also advantageous, from the standpoint of biofouling prevention, that this mixing occur at some distance from the injection wells.
\end{abstract}

\section{Introduction}

It has been recognized for several years now that pump-andtreat remediation may require decades or even centuries to return chlorinated solvent contaminated aquifers to a condition where the water meets drinking water quality standards [Mackay and Cherry, 1989]. Such lengthy programs can be undertaken only at great expense. Some of these expenses might be reduced or eliminated if more passive, in situ, remedial alternatives can be developed. One example of such an alternative is the semipassive nutrient injection system for bioremediation, described by Devlin and Barker [1994]. This method operates passively $99 \%$ of the time, limiting power and maintenance expenses, and the nutrients added to the subsurface are introduced in a fashion that promotes dispersive mixing between the injected solution and the ambient groundwater; such mixing is not promoted in systems based on continuously operating injection and withdrawal wells. Complete mixing between the nutrient solution and the groundwater is necessary if the subsurface microorganisms are to be stimulated and degrade pollutants at the same time. The nutrient injection system comprises a permeable wall installed across the entire width and depth of a contaminant plume, perpendicular to the average flow direction. The wall is instrumented with injection and withdrawal wells and is constructed with a material that is more permeable than the surrounding aquifer so that during the flushing procedure, water recirculates primarily through the wall and not through the surrounding aquifer. In the first stage of operation, the water contained in the pore spaces of the wall is extracted, amended with the desired chemical substances, and reinjected. This procedure occurs over a period of hours. Once the injected substances have swept through the wall (about 1 pore volume for unretarded substances), the pumping systems are turned off. In the second stage of operation, the slug of remedial solution just introduced is transported out of the wall under natural gradient conditions. Depending on the geometry of the slug and the normal flow conditions for a given site, this process occurs over

Copyright 1996 by the American Geophysical Union.

Paper number 96WR01128.

0043-1397/96/96WR-01128\$09.00 a period of weeks or months. In some cases, where groundwater flow rates are particularly high ( $\sim 1 \mathrm{~m} / \mathrm{d}$ or greater), the second stage may occur over a period of days. As the slug is transported, it undergoes dispersive mixing with the natural groundwater. This stage is entirely passive. Once the nutrient slug is flushed out of the wall and has been transported some small distance downgradient, stages 1 and 2 are repeated. This cycle is continued for the duration of the bioremediation program. The effect of pulsing the nutrient slugs in this fashion is to produce a zone in the aquifer, some distance outside and downgradient from the wall, where microorganisms receive a continuous supply of required nutrients, etc., completely mixed with whatever contaminant is being transported in the groundwater, by longitudinal dispersion. It is in this zone where biodegradation of the target pollutants would be most likely to occur. The fact that the wall is established across the width and depth of the plume obviates the need for mixing in directions transverse to the flow direction. This method of injection minimizes the displacement of contaminated water, so that dispersive mixing can occur over minimal distances downgradient from the wall.

The operation of the system described above was shown to be feasible in principle by Devlin and Barker [1994]. However, field verification was required to evaluate the actual system performance in a heterogeneous aquifer where nutrients could be utilized as well as transported and dispersed. Such a field experiment was conducted at Canadian Forces Base (CFB) Borden, Ontario, immediately next to the site of a previously reported organic tracer experiment [Mackay et al., 1986]. The objectives of the study included (1) to determine whether groundwater amended with a carbon substrate could be reintroduced to the subsurface uniformly through a permeable wall, (2) to evaluate the mixing of nutrient pulses in the aquifer (after they had migrated out of the wall), and (3) to stimulate anaerobic microbial activity and use geochemical indicators to monitor the changing redox conditions in the aquifer.

\section{Description of the Study Site}

Various aspects of the study site have been described in detail elsewhere [MacFarlane et al., 1983; Egboka et al., 1983; 


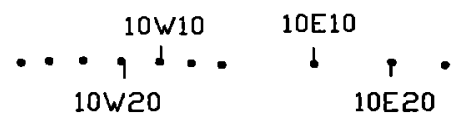$$
\cdot i_{5 w 20}^{5 W 15} 5 w 10
$$
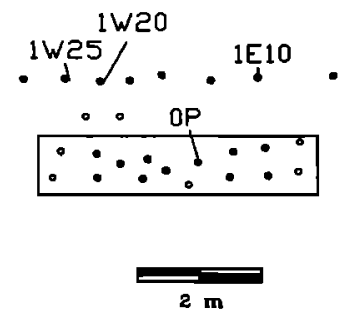

Figure 1. Locations of wells and monitors. Open circles represent pumping and injecting wells. Solid dots represent multilevel monitors.

Mackay et al., 1986; Ball et al., 1990]. Briefly, the study was conducted in the top $4.5 \mathrm{~m}$ of a sand aquifer at the CFB Borden test site. Beneath the test zone, at depths of 5 to $9 \mathrm{~m}$, there is a leachate plume emanating from a landfill located several hundred meters upgradient.

Bulk aquifer samples collected at the study site as part of this investigation were analyzed by the dry sieve method. Two visually different samples were collected during the installation of the permeable wall. The first, a fine sand, was considered representative of the majority of the local aquifer sediment; the second was recovered from a seam of coarse material that was intersected over the depth range $2.74 \mathrm{~m}-2.89 \mathrm{~m}$ below surface. Applying Hazen's rule [Freeze and Cherry, 1979] to the aquifer grain size curves indicated that the saturated hydraulic conductivity $K$ was estimated to be in the range $8.5 \times 10^{-5} \mathrm{~m} / \mathrm{s}$ to $1.1 \times 10^{-4} \mathrm{~m} / \mathrm{s}$. A similar analysis using the method of Alyamani and Sen [1993] yielded a $K$ range of $7.7 \times 10^{-5}$ to $1.0 \times 10^{-4} \mathrm{~m} / \mathrm{s}$. These values are within the expected range based on the previous work cited above.

Water level measurements made over the course of the study indicated a typical water table depth of about $1 \mathrm{~m}$ and an average gradient of 0.005 . The average groundwater velocity was about $0.10 \mathrm{~m} / \mathrm{d}$, and the aquifer porosity has been estimated to be 0.33 [Ball et al., 1990].

Prior to any acetate injections the experimental zone of the aquifer was characterized geochemically in order to establish its initial redox state. Dissolved oxygen was present up to 6 $\mathrm{mg} / \mathrm{L}$ in the shallowest sampling locations ( $1 \mathrm{~m}$ below surface) but decreased to a range of $<0.1-0.3 \mathrm{mg} / \mathrm{L}$ at depths exceeding $2 \mathrm{~m}$. No nitrogen species were detected above the detection limit of the method used $(0.01 \mathrm{mg} / \mathrm{L})$. However, both iron and manganese were detected at concentrations of up to $0.3 \mathrm{mg} / \mathrm{L}$ and $0.1 \mathrm{mg} / \mathrm{L}$, respectively, in locations where dissolved oxygen was below the detection limit $(0.1 \mathrm{mg} / \mathrm{L})$. Sulfate was present at concentrations between about $10 \mathrm{mg} / \mathrm{L}$ and $30 \mathrm{mg} / \mathrm{L}$ throughout the upper $4 \mathrm{~m}$ of the aquifer. These data are consistent with those of Nicholson et al. [1983], who conducted a thorough redox survey of the Borden aquifer in their characterization of the leachate plume. Based on an analysis of several redox couples and field Eh measurements, they concluded that nearequilibrium conditions existed between $\mathrm{Fe}(\mathrm{OH})_{3}$ (s) and $\mathrm{FeCO}_{3}(\mathrm{~s})$, resulting in a pe for the system poised between 4 and 6. Methane was not detectable in any of the background samples collected. Below a depth of $4.5 \mathrm{~m}$, landfill leachate was encountered, characterized by relatively high concentrations of so$\operatorname{dium}(\sim 100 \mathrm{mg} / \mathrm{L})$, magnesium $(\sim 50 \mathrm{mg} / \mathrm{L})$, iron $(\sim 10 \mathrm{mg} / \mathrm{L})$, chloride $(\sim 100 \mathrm{mg} / \mathrm{L})$, and sulfate $(\sim 300 \mathrm{mg} / \mathrm{L})$.

\section{Experimental Design \\ Design of the Permeable Wall}

A pilot scale permeable wall was installed in the shallow unconfined sand aquifer at CFB Borden. The test wall was constructed by driving sealable sheet piles into the ground to a depth of $6 \mathrm{~m}$, enclosing an area $4 \mathrm{~m}$ long by $1 \mathrm{~m}$ wide. This cell was dewatered, excavated to a depth of $4.5 \mathrm{~m}$, instrumented, and backfilled with filter sand. The aerial dimensions were the minimum possible with the installation methods used; the depth was chosen so that the wall would lie above the zone of leachate contamination.

The material used to backfill the wall comprised sand and gravel obtained from a local quarry. The material was selected on the basis of its hydraulic properties relative to those of the surrounding aquifer [Driscoll, 1986; Devlin, 1994a]. The hydraulic conductivity of the filter sand was estimated to be between $1.3 \times 10^{-4} \mathrm{~m} / \mathrm{s}$ and $3.6 \times 10^{-4} \mathrm{~m} / \mathrm{s}$. This corresponds to a maximum hydraulic conductivity contrast with the aquifer of about a factor of 5 .

The placement of the pumping and injecting wells, and the pumping rates were determined on the basis of twodimensional simulations of the system using FLOWPATH [Franz and Guiger, 1992]. It was found that the wall could be flushed efficiently with injection wells at each corner, and two pumping wells located symmetrically about the center. Total pumping rates between $18 \mathrm{~L} / \mathrm{min}$ and $37 \mathrm{~L} / \mathrm{min}$ (5-10 U.S. gallons per minute (gpm)) were found to exchange the wall water within 6 to 8 hours.

\section{Monitoring Network}

A total of eight multilevel bundle piezometers were installed in the permeable wall to monitor the introduction of nutrients by flushing and the subsequent transport of nutrients out of the wall under natural gradient conditions. The remainder of the monitoring network was installed in three "fences" aligned approximately perpendicular to the average direction of groundwater flow. The fences were located $1 \mathrm{~m}, 5 \mathrm{~m}$, and $10 \mathrm{~m}$ from the downgradient side of the wall and consisted of multilevel bundle piezometers (Figures 1 and 2). A naming convention was adopted that would convey information about monitor locations in the network and that could accommodate the addition of new monitors at later times. Monitor names consisted of five parts: (1) a number referring to the distance from the wall in meters; (2) a letter, either E or W, depending on whether the monitor was located to the east or west of the center of the monitoring network; (3) a second number indicating the relative position of the monitor on the fence, with larger values for monitors farther away from the center (in either direction); (4) a second letter (P or I) indicating whether the well was used for pumping or injecting; and (5) a number following a hyphen referred to the relative vertical position of 
a sampling point, counting from the deepest location upward. For example, monitor 5E10 was located on the 5-m fence, on the east side of the network. 5E10-1 referred to the deepest sampling port on monitor 5E10. The designation $0 \mathrm{P}$ referred to a pumping well near the center of the permeable wall (see Figure 1).

The multilevel monitors were constructed with 0.5 -inch (1.27 $\mathrm{cm}$ ) polyvinyl chloride (PVC) central stocks supporting either fine polyethylene (PE) or polytetrafluoroethylene (PTFE) sample tubing. In both construction designs the sample tubes were strapped to the stock with nylon clips and screened with Nytex mesh (200 mesh).

\section{Injection of Primary Substrate and Tracers}

Regular injections of a solution of potassium acetate (hereinafter referred to as the "nutrient solution") were conducted to supply the subsurface microorganisms with a labile organic substrate. The first two of these injections also contained the inorganic tracers (sodium) chloride and (sodium) bromide, respectively. The regular injections were performed by pumping water from the center of the wall, amending it in-stream with the acetate and tracers, and reinjecting the amended solution at the ends of the wall to form two recirculation cells. Flow to and from the wall was controlled with an arrangement of flow meters and valves (Figure 3).

The recirculation system was driven by a gasoline-powered Honda WH15XC pressure pump. Flow rates were measured using Cole Palmer L-03248-66 flow meters with maximum capacities of 15 U.S. gpm $(57 \mathrm{~L} / \mathrm{min})$. A water-driven automatic proportional feeder (APF) pump (Autotrol Corporation, Milwaukee, Wisconsin) was used for the in-line amendments. Standard white line, flexible black PE plumbing pipe was used throughout the system. Elbows and joints in the tubing were made of PVC or nylon, and all valves were made of brass. All parts were held in place with hose clamps; no glue was used in any part of the system construction.

The acetate injections were conducted at intervals of 5-7 weeks. Altogether, $33 \mathrm{~kg}$ of acetate were introduced to the aquifer in 11 injections over 62 weeks.

\section{Data Collection and Analysis Chemical Analysis}

Conductivity data were collected with a conductivity manifold designed for this experiment. The apparatus permitted

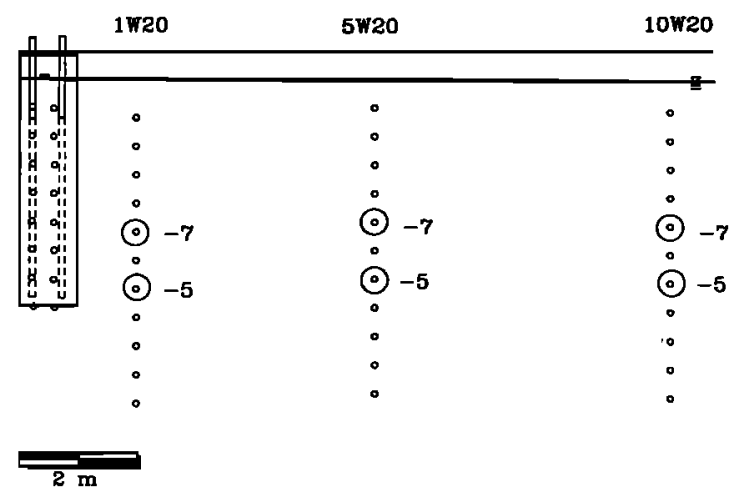

Figure 2. Cross section along the W20 sampling line. Open circles represent multilevel monitoring point locations. Double circles are points specifically discussed in the text or other figures.

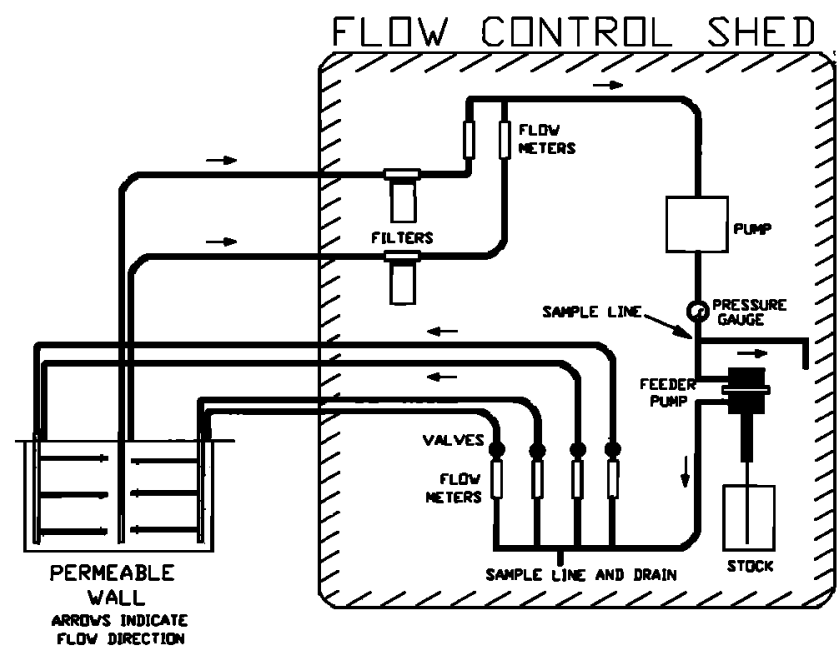

Figure 3. Schematic diagram of the injection system.

simultaneous collection of eight samples (in 20-mL PE bottles) and measurement of their conductivities prior to preservation and storage. The conductivity measurements were used to monitor real-time progress of acetate, chloride, and/or bromide through the wall and aquifer. Following the conductivity measurement, samples could be removed from the manifold, amended with preservatives, and placed in a cooler for further analysis in the laboratory. All samples were preserved with 0.2 $\mathrm{mL}$ of a $10 \%$ sodium azide solution to prevent aerobic degradation of acetate during storage. A 6-month storability study indicated that the preservation steps were effective in preventing acetate degradation in the sample bottles over the time frame relevant to this study.

Additional samples were occasionally collected for more detailed geochemical analyses. Cation samples $\left(\mathrm{Na}^{+}, \mathrm{K}^{+}\right.$, $\mathrm{Mg}^{2+}, \mathrm{Ca}^{2+}, \mathrm{Fe}^{2+}, \mathrm{Mn}^{2+}$ ) were drawn directly from the ground into precleaned and rinsed $60-\mathrm{mL}$ polypropylene syringes, and then transferred through $0.45-\mu \mathrm{m}$ filter membranes to clean, dry polystyrene sample bottles containing a few drops of concentrated nitric acid. The samples collected for anion analysis $\left(\mathrm{Cl}^{-}, \mathrm{SO}_{4}^{2-}, \mathrm{NO}_{3}^{-}, \mathrm{NO}_{2}^{-}, \mathrm{PO}_{4}^{3-}, \mathrm{HCO}_{3}^{-}\right)$were collected in the same way as those for cations, without the nitric acid preservative. All samples were stored on ice in a cooler until delivery to the laboratory. Cation analyses were performed by atomic absorption spectrometry using a Varian model 1475 atomic absorption spectrophotometer. Anions, except bicarbonate, were analyzed by ion chromatography using a Dionex System 2000 ion chromatograph with a Dionex AS3 or AS4A anion exchange column, a Dionex micro membrane suppresser column and a Dionex model 430 conductivity detector. Bicarbonate was determined in samples not containing acetate by titration to $p H 4.3$ with standardized sulfuric acid using a Metrohm autotitration unit. Analyses of duplicate samples indicated that the analytical precision was within 5\%. All analyses were performed by the Water Quality Laboratory at the University of Waterloo.

\section{Breakthrough Curve Analysis}

Breakthrough curves for chloride and acetate at monitoring points in the wall (during flushing) and in the aquifer were analyzed using one-dimensional solutions to the advectiondispersion equation. Data collected during wall flushing were 
fit to the Ogata-Banks solution [Ogata and Banks, 1961]; data from the 1-m fence were fit to equation (1) below (adapted from Sudicky and Cherry [1979]), which assumes instantaneous equilibrium sorption according to a linear isotherm, first-order transformation kinetics, and an infinite domain. At time $=0$, a pulse of width $w$ is centered at $x=0$.

$$
\begin{aligned}
C(x, t)= & \frac{\text { Co }}{2}\left[\operatorname{erfc} \frac{x-w /(2 R)-v t / R}{2(D t / R)^{1 / 2}}\right. \\
& \left.-\operatorname{erfc} \frac{x+w /(2 R)-v t / R}{2[D(t-w / v) / R]^{1 / 2}}\right] \exp [-\lambda t]
\end{aligned}
$$

where

$$
\begin{aligned}
& D=v \alpha+D^{*} \\
& R=1+\frac{\rho_{b}}{\theta} K_{d}
\end{aligned}
$$

$C(x, t)$ is solute concentration $\left(M / L^{3}\right)$, Co is injection concentration $\left(M / L^{3}\right), R$ is retardation factor (dimensionless), $x$ is distance from the central axis of wall $(L), w$ is source width of a conservative substance $(L), v$ is average linear groundwater velocity $(L / T), t$ is time $(T), \alpha=$ dispersivity $(L), D^{*}$ is effective diffusion coefficient of solute $\left(L^{2} / T\right), \lambda$ is firstorder decay constant $\left(T^{-1}\right), \rho_{b}$ is aquifer bulk density $(M /$ $L^{3}$ ), $\theta$ is porosity (dimensionless), and $K_{d}$ is partition coefficient $\left(L^{3} / M\right)$. Equation (1) assumes that the first-order degradation begins with $t>0$. Injection concentrations were taken as those measured at similar depths in the permeable wall. With these values fixed, the total mass in a stream tube was determined by the source width term. It was assumed for chloride that $R=1$ and $\lambda=0$.

With (1) it is necessary to know the source conditions for a given stream tube. While it was possible to obtain reasonable estimates of the source parameters for stream tubes intersecting the $1-\mathrm{m}$ fence, it was virtually impossible to know the source conditions applicable to breakthrough curves 5 and $10 \mathrm{~m}$ from the source. The source width and concentration distribution in the permeable wall were not perfectly uniform, and over a linear travel distance of $5 \mathrm{~m}$ or greater, the travel paths in the aquifer may have been quite tortuous. Therefore a second solution to the advection dispersion equation was adopted for analyzing breakthrough curves at the 5-m and 10-m fences [Kinzelbach, 1987, 209]:

$$
C(x, t)=\frac{M /(\theta R)}{(4 \pi D t / R)^{1 / 2}} \exp \left[\frac{-(x-v t / R)^{2}}{4 D t / R}-\lambda t\right]
$$

where $M$ is mass input to the stream tube sampled $(M)$. With (4), knowledge of source concentration and exact travel path is unnecessary; breakthrough curves can be integrated directly for an estimate of $M$ and then solved.

In equations (1) and (4), the aquifer is treated as a collection of stream tubes or columns extending directly from the source to the sampling points. A given sampling point provides information only about the stream tube in which it is located; mass transfer between stream tubes is assumed negligible.

The chloride breakthrough curves were fit to either (1) or (4) to obtain values for the source width (for equation (3)) or stream tube source mass (for equation (4)), the average linear velocity, and the dispersion coefficient. The optimized fits were obtained using the simplex optimization algorithm to minimize the residuals sum of squares function, as discussed by Devlin [1994b].

\section{Results and Discussion}

\section{Flow in and Around the Wall During Nutrient Injection}

Detailed monitoring of chloride movement through the wall during the first flushing procedure indicated that vertical velocity variations existed. Nevertheless, for all practical purposes, when the flushing was concluded, the injected solution was distributed in a reasonably uniform fashion throughout the wall. In addition, both calculations based on measured gradients within the wall during flushing and calculations based on velocities determined from tracer breakthrough curves, indicated that about $90 \%$ of the water pumped during the flushing procedure was circulated in the wall [Devlin, 1994a]. From this it is inferred that there was a minimal effect on the natural flow system caused by the wall flushing.

\section{Dispersion and Pulse Mixing}

The progress of the chloride pulse (first injection) was monitored at the $1-\mathrm{m}, 5-\mathrm{m}$, and $10-\mathrm{m}$ fences to establish the dispersive characteristics of the aquifer (Figure 4, Table 1). These were then used to assess the merging of the acetate pulses which followed. The acetate pulses could not be interpreted on their own because they were subject to mass loss, due to biodegradation, and in many cases the complete pulses were obscured as a result of merging.

The problem of assessing the mixing of pulses was addressed by Roberts et al. [1990] in their efforts to deliver dissolved oxygen to methanotrophic bacteria. They calculated amplitude ratios for various pulse periods to predict the optimum conditions for mixing within $1 \mathrm{~m}$ of the source. However, they found that the modeled data overpredicted the amount of pulse mixing when Peclet numbers representative of their field site were used in the simulations. For the purposes of this investigation, an approach based on pulse variances was developed.

According to Bear [1961], a tracer pulse may be described using a normal frequency function similar in form to (4). Ignoring molecular diffusion, the standard deviation of the function is given by

$$
\sigma=(2 D \bar{x} / v)^{1 / 2}
$$

where $\sigma$ is standard deviation $(L), \bar{x}$ is distance from source to centroid of pulse $(L), D$ is dispersion coefficient $\left(L^{2} / T\right)$, and $v$ is average linear transport velocity $(L / T)$. The variance of a pulse, $\sigma^{2}$, may be estimated by the square of its standard deviation [Bear, 1961]. As a tracer pulse migrates away from the source and begins to spread out, its variance increases. This will occur linearly with time if the dispersion process is Fickian. If two conservative tracer pulses of duration $t_{0}$ are released $\Delta t$ days apart in an aquifer where the average linear groundwater velocity is $v$, there is a minimum amount of spreading necessary for them to merge, which corresponds to a variance $\sigma_{\text {min }}^{2}$ (Figure 5). Merging may be considered to begin when at a distance $d$ from the source, each pulse has spread out to the degree that $2 \sigma=v \Delta t / 2$. If this condition is fulfilled, then as a first approximation, the pulses must just merge when the centroids are at distances $v \Delta t / 2$ and $-v \Delta t / 2$ from $d$. By this reasoning, the minimum variance required for the two pulses to mix is a function of the groundwater velocity and their initial separation time, 
1 W20-7

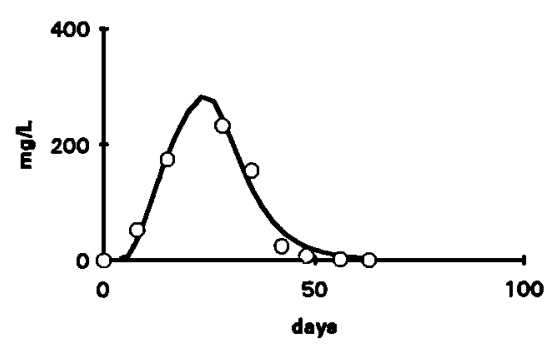

1 W20-5

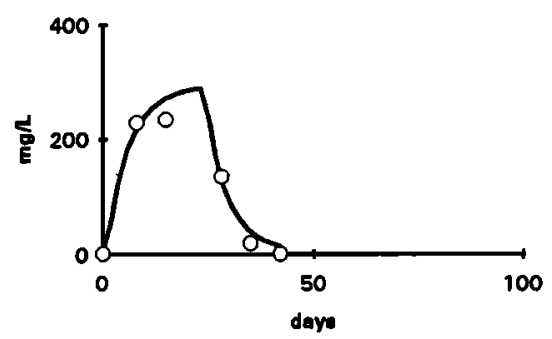

5W20-7

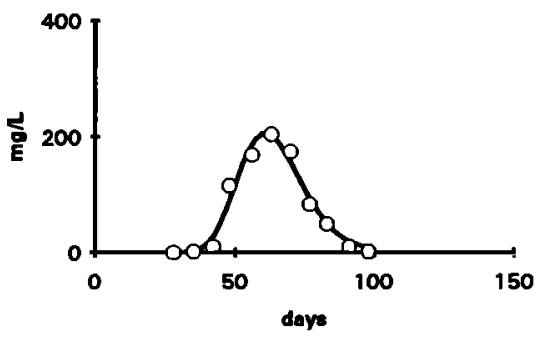

5W20-5

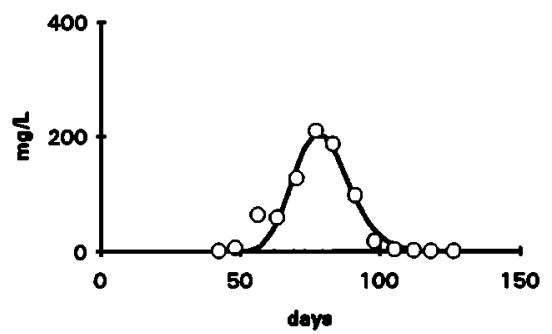

10w20-7

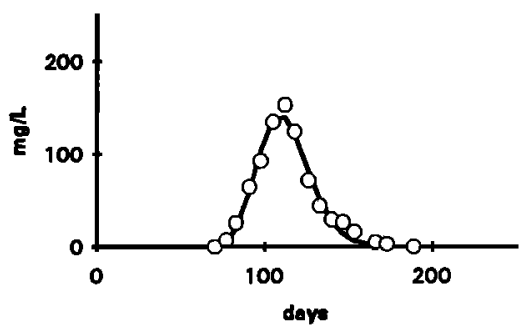

10W20-5

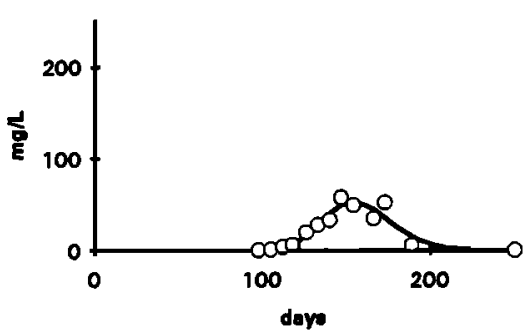

Figure 4. Best fit solutions to equations (1) (1W20 locations) and (4) (all other locations) to chloride data from selected monitoring locations. Solid lines are modeled fits, and circles are experimental data points.

$$
\sigma_{\min }^{2}=(v \Delta t / 4)^{2}
$$

Nonreactive pulses with variances greater than $\sigma_{\min }^{2}$ will mix, and those with lower variances will not.

The first two acetate injections were conducted 5 weeks apart. Two field criteria were adopted to assess the actual merging of the two pulses; merging was considered to have occurred if either (1) the acetate concentrations did not drop below the detection limit between the pulses, or (2) the chloride concentration from the first injection remained at least 5 $\mathrm{mg} / \mathrm{L}$ above background when the second acetate pulse appeared. The chloride pulse variances where these criteria were met, are indicated in Figure 6. Also plotted are the minimum variances for pulse periods between 4 and 7 weeks (from equation (6)), assuming an average linear velocity for the site of 0.1 $\mathrm{m} / \mathrm{d}$. It can be seen that a period of 5-6 weeks promotes mixing in many locations as close as $5 \mathrm{~m}$ from the source, while a 7 -week period is too large to ensure mixing within $10 \mathrm{~m}$ of the source in many of the stream tubes.

Equation (6) can be adapted for use in design calculations by combining it with equation (5). It can be shown that the pulse period $\Delta t$ required for a given site is a function of the longitudinal dispersion coefficient $D_{x}$ and the groundwater velocity $v$,

$$
\Delta t=\left(\frac{32 D_{x} \bar{x}}{v^{3}}\right)^{1 / 2}
$$

where $\bar{x}$ is the distance from the source over which mixing must occur $(L)$. It should be noted that (7) ignores the contribution of the pulse width at time $t$ from the initial pulse width $w$. Thus the relationship really applies only for cases where $\bar{x}$ is large in comparison with $w$. However, it may be considered conservative at lower values of $\bar{x}$ (i.e., smaller than required values of $\Delta t$ will be calculated). Hunt [1978] presented a criterion by which the equivalency of equations (1) and (4) could be tested. With minor modifications, that criterion can be used to define the range of over which (7) is theoretically valid (maximum concentrations calculated from (1) and (4) will agree to within $5 \%)$ :

$$
\bar{x} \geq \frac{v w^{2}}{2.4 D_{x}}
$$

\begin{tabular}{|c|c|c|c|c|c|c|}
\hline \multirow[b]{2}{*}{ Well } & \multirow{2}{*}{$\begin{array}{l}\text { Sampling } \\
\text { Point }\end{array}$} & \multirow{2}{*}{$\begin{array}{c}\text { Distance } \\
\text { From Wall, } \\
\text { m }\end{array}$} & \multirow{2}{*}{$\begin{array}{c}\text { Elevation, } \\
\text { mabw }\end{array}$} & \multicolumn{3}{|c|}{ Chloride } \\
\hline & & & & Velocity, $\mathrm{m} / \mathrm{d}$ & $\alpha, m$ & $D x, \mathrm{~m}^{2} / \mathrm{s}$ \\
\hline \multirow[t]{2}{*}{$1 \mathrm{~W} 20$} & 5 & 1.532 & 0.349 & 0.097 & 0.198 & 2.21E-07 \\
\hline & 7 & 1.532 & 1.349 & 0.065 & 0.115 & 8.59E-08 \\
\hline \multirow[t]{2}{*}{$5 W 20$} & 5 & 5.622 & 0.464 & 0.073 & 0.045 & $3.80 \mathrm{E}-08$ \\
\hline & 7 & 5.622 & 1.464 & 0.092 & 0.097 & $1.03 \mathrm{E}-07$ \\
\hline \multirow[t]{2}{*}{$10 \mathrm{~W} 20$} & 5 & 10.656 & 0.369 & 0.069 & 0.093 & $7.36 \mathrm{E}-08$ \\
\hline & 7 & 10.656 & 1.369 & 0.097 & 0.102 & $1.14 \mathrm{E}-07$ \\
\hline Mean & & & & $0.101 \pm 40.2 \%$ & $0.090 \pm 65.5 \%$ & $1.08 \mathrm{E}-07 \pm 90.9 \%$ \\
\hline
\end{tabular}

Table 1. Estimated Dispersion Parameters From Selected Sampling Locations

The means and standard deviations for all 26 sampling locations are given. All dispersivities $\alpha$ were fitted assuming a molecular diffusion coefficient of $10^{-10} \mathrm{~m}^{2} / \mathrm{s}$. The unit mabw is meters above the bottom of the wall. Read $2.21 \mathrm{E}-07$ as $2.21 \times 10^{-7}$. 


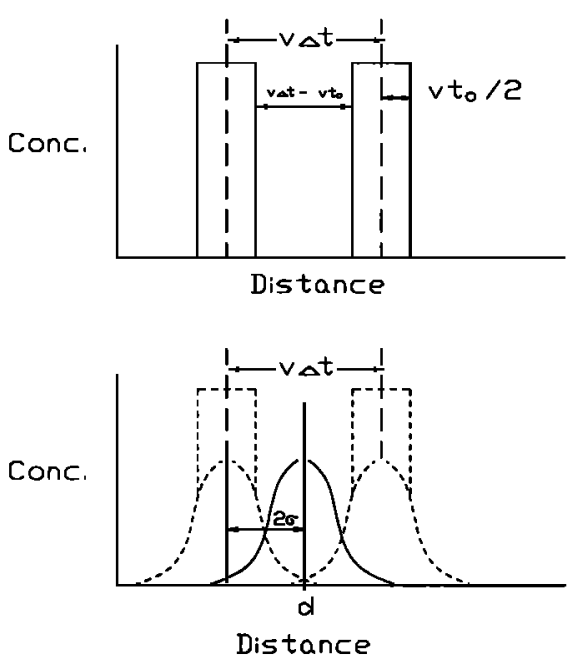

Figure 5. Merging of two pulses. (top) Plug flow. (bottom) Conditions for dispersive mixing.

As an example of the usage of these equations, consider the following scenario representative of average conditions in the Borden aquifer (Table 1): $v=0.10 \mathrm{~m} / \mathrm{d}$, and $D_{x}=1.08 \times$ $10^{-7} \mathrm{~m}^{2} / \mathrm{s}$, and the source wall width is $1 \mathrm{~m}$. From (8) the minimum distance is calculated to be about $4.5 \mathrm{~m}$. Thus (7) can be used to determine $\Delta t$ for the $5-\mathrm{m}$ fence. When this is done, $\Delta t$ is calculated to be 6 weeks.

In many environments where mixing is an issue, mechanical dispersion will be more important in the longitudinal direction than molecular diffusion, i.e., $D_{x}=v \alpha$. In these cases, the equations above are valid, and reasonable estimates of dispersivity will be critical. It should also be noted that although diffusion may be unimportant in the direction of flow, transverse diffusion may still be a process of significance.

\section{Sampling Scale}

Groundwater samples were collected from sampling ports that were small in relation to the aquifer heterogeneities. This

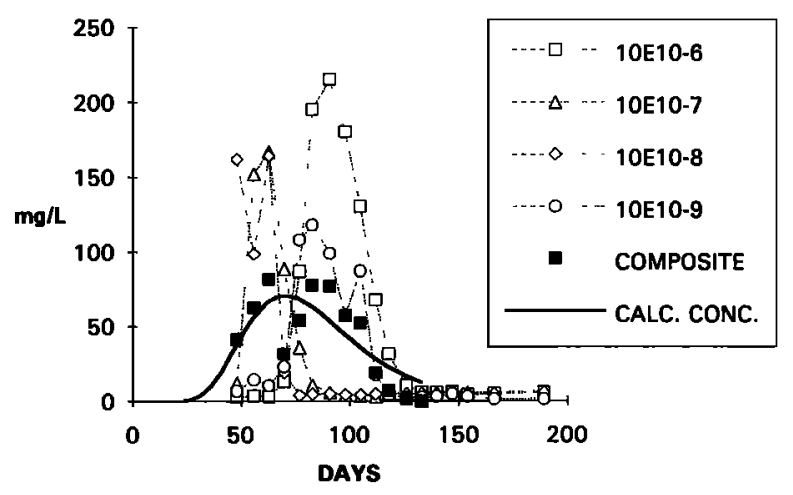

Figure 7. Effect of sampling scale. The apparent mixing indicated by the composite sample (solid line) is not representative of the mixing on a smaller scale (multilevel monitor scale, dashed lines).

scale of sampling should reflect, as closely as possible, the acetate concentrations experienced by the indigenous bacteria. However, in many situations this type of sampling might not be practical. In order to assess the effect of sampling scale on the degree of apparent mixing in the aquifer, the concentrations from well 10E10, levels $6,7,8$, and 9 (elevations 0.954 to 2.454 $\mathrm{m}$ above the bottom of the wall (mabw)) were arithmetically averaged to approximate a composite breakthrough curve such as one might obtain by sampling from a $1.5-\mathrm{m}$ screen at the same location (Figure 7). The composite curve was fit to (4) with the result that the average linear velocity was estimated to be $14 \mathrm{~cm} / \mathrm{d}$ and the dispersion coefficient was estimated at $1.04 \times 10^{-6} \mathrm{~m}^{2} / \mathrm{s}$. With these values, the largest pulse period possible that would still ensure mixing is calculated from (7). When this is done, a period of 14 weeks is obtained. It is apparent from the detailed sampling data that such a large interval between pulses would fail to provide a sustained acetate supply to the bacteria, although it might appear to from the data derived from the larger sampling scale. This calculation demonstrates the need for small-scale sampling to prop-

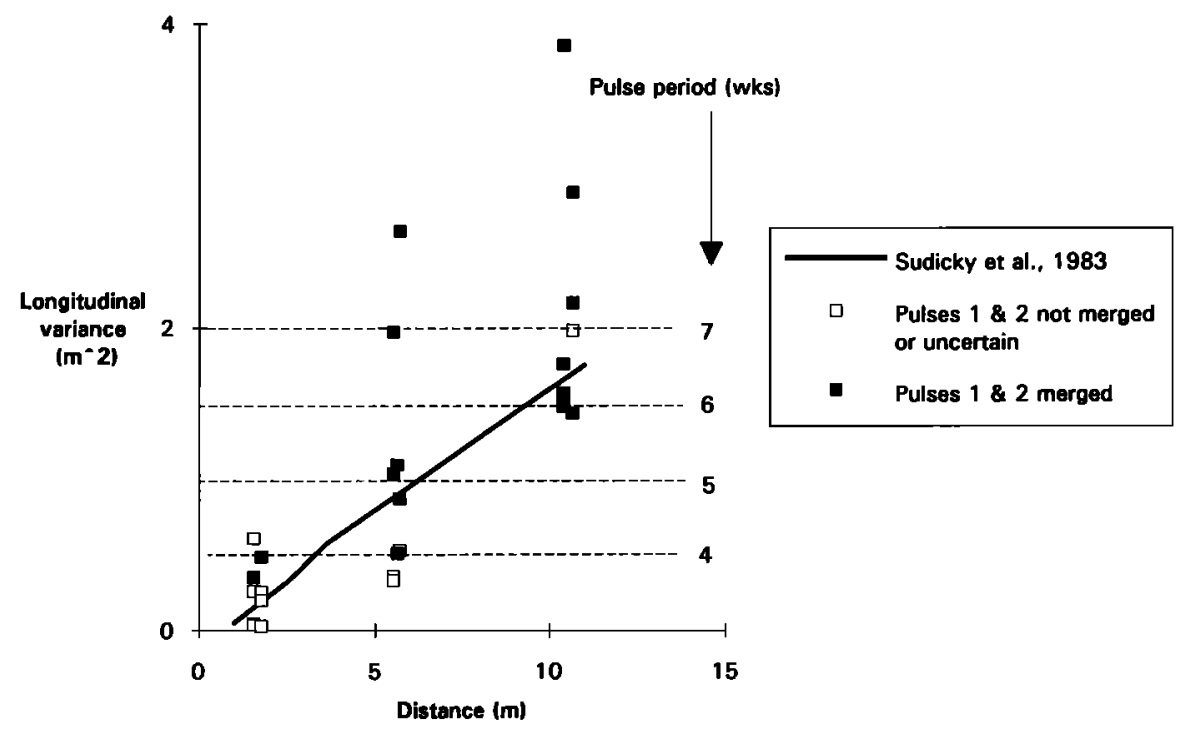

Figure 6. Variances for stream tube pulses at the 1-m, $5-\mathrm{m}$, and $10-\mathrm{m}$ fences. Also plotted are minimum variances for mixing for various pulsing intervals. 
D.O. PROFILE BEFORE INJECTIONS

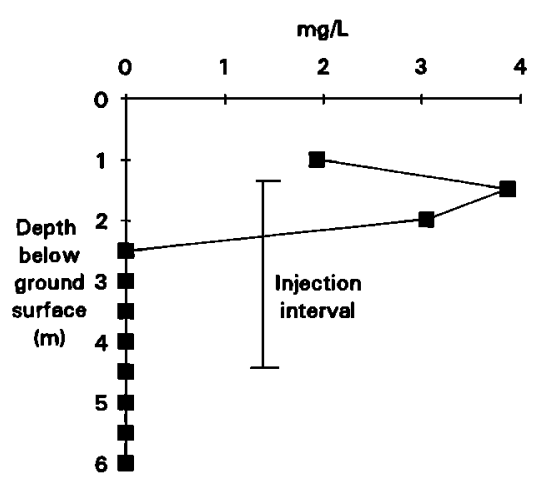

D.O. PROFILE AFTER INJECTIONS

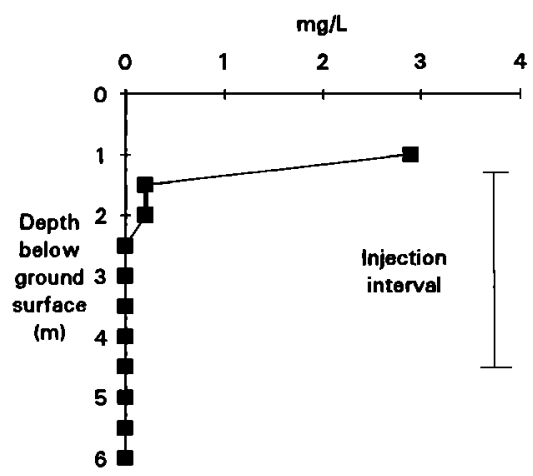

Figure 8. Dissolved oxygen profiles at $5 \mathrm{~W} 20$ before and after acetate injections.

erly assess the consistency of the supply of injected nutrients to bacteria. Since these organisms live on a microscopic scale, macroscopic averaging of the mixing process, in the course of sampling or modeling, may be misleading.

\section{Redox Changes Accompanying the Injections}

Once the acetate injections were underway, there was an increased oxygen demand in the aquifer and a reduced thickness of aerobic water at the water table (Figure 8); at 5W20, dissolved oxygen was either absent or present only at detection limits at elevations below those of the tops of the injection well screens (in the wall). Further evidence of a declining pe in the aquifer was the reduction in sulfate concentrations at most monitored points (Figure 9). This suggests that the redox environment had been altered to one of sulfate reduction. A strong hydrogen sulfide odor in the samples taken from the site was noted soon after the acetate injections began, which supports the notion that sulfate reduction was occurring.

The first two pulses were injected 5 weeks apart, while the second and third pulses were injected 7 weeks apart. In many locations along the 5-m and 10-m fences, the first two pulses merged sufficiently that sulfate reduction was continuous while both pulses migrated past. However, mixing between the second and third pulses was insufficient to maintain the sulfatereducing population, and sulfate concentrations rose to nearbackground levels (15 to $20 \mathrm{mg} / \mathrm{L}$ at these depths) between the pulses. This geochemical evidence supports the dispersion calculations presented above, which indicated that a 6-week interval was the maximum for mixing at the $5 \mathrm{~m}$ fence, assuming average conditions for the site. Furthermore, these data indicate that the mixing in evidence at the sampling scale also occurred on the scale of the microorganisms.

As a final assessment of the postinjection redox state of the aquifer, samples were collected from the $1-\mathrm{m}, 5-\mathrm{m}$, and $10-\mathrm{m}$ fences for methane analysis (Figure 10). Methane was detected at each fence, and in increasing concentration with distance from the permeable wall. Methane was absent from samples collected from adjacent locations before the acetate additions.

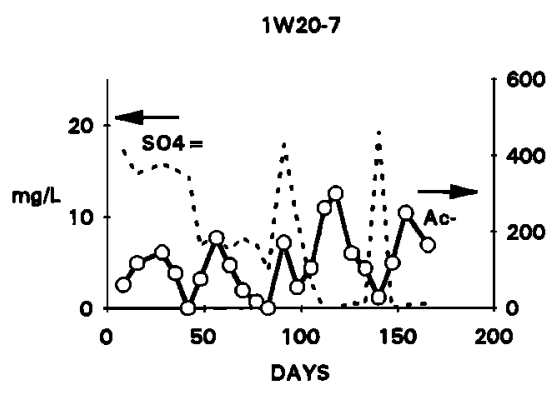

1W20-5

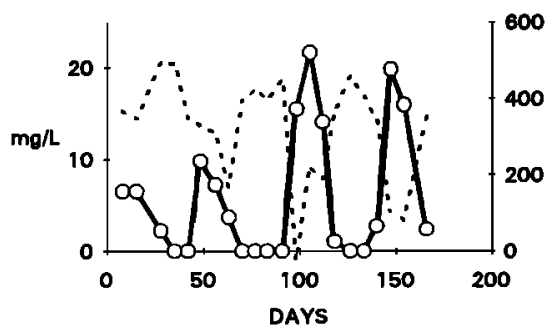

5W20-7

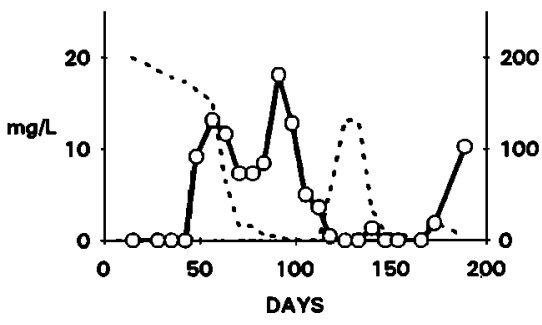

5W20-5

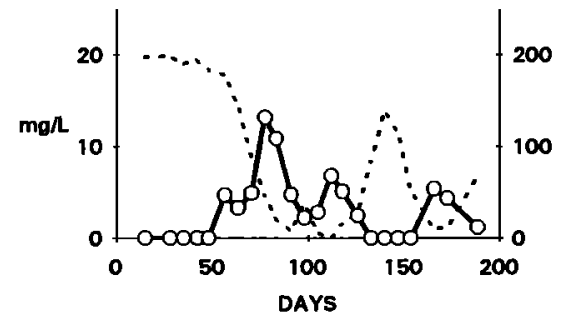

10W20-7

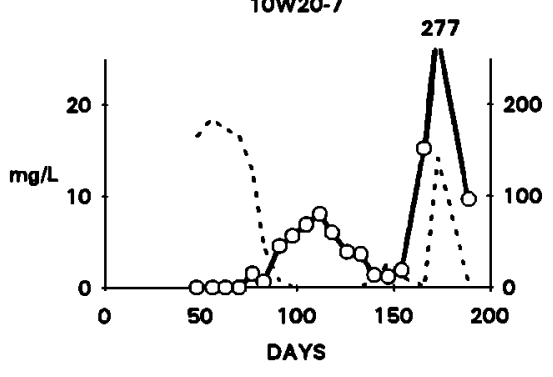

10 20-5

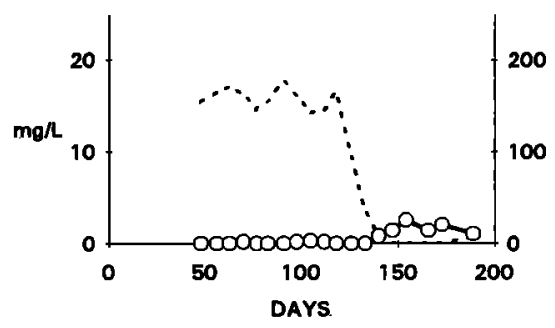

Figure 9. Breakthrough curves of acetate (solid lines and circles) and sulfate (dashed lines) at two depths along the W20 sampling line. Sulfate reduction is indicated where sulfate concentrations fall below background (15-20 mg/L). 

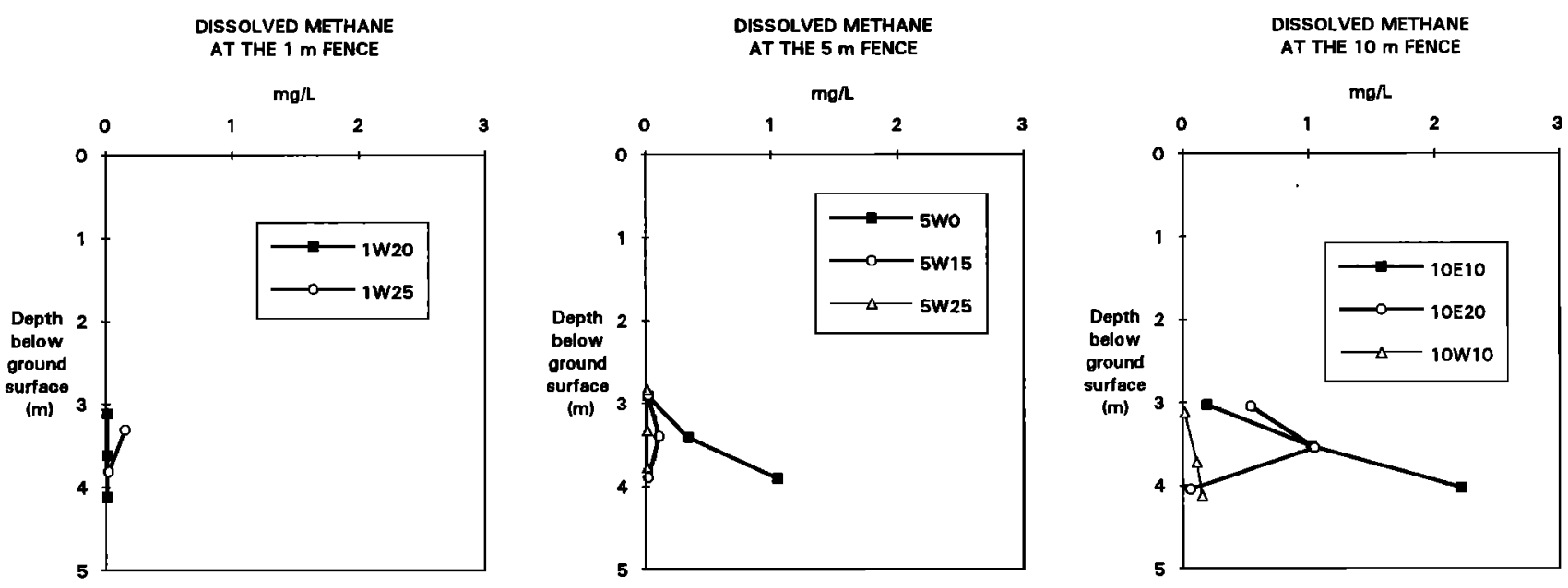

Figure 10. Methane profiles at the 1-m, 5-m, and 10-m fences.

This establishes that methanogenesis was stimulated in the aquifer within the entire 10-m test site. Reductive dechlorination is most favored under methanogenic conditions, so this change in the aquifer environment is very significant for a possible remedial design. However, the profiles also show that the methane concentrations were not uniform. This suggests that the methanogenic bacteria were active in only selected portions of the aquifer. The highest concentrations of methane were in the range $1-2.2 \mathrm{mg} / \mathrm{L}$ and were detected at wells $5 \mathrm{~W} 0$, $10 \mathrm{E} 10$, and $10 \mathrm{E} 20$, at depths of 3-4 m. This concentration range is less than $10 \%$ of saturation $(30 \mathrm{mg} / \mathrm{L})$ at $10^{\circ} \mathrm{C}[$ Perry and Green, 1984, p. 3-103), further indicating that the activity was limited.

\section{Conclusions}

A permeable wall was installed in a shallow, unconfined sand aquifer. Detailed monitoring of a tracer test demonstrated that the wall could be flushed with reasonable uniformity over the vertical portion spanned by the pumping and injecting well screens. Head measurements and an analysis of the tracer data indicated that ambient flow in the surrounding aquifer was affected only minimally by the flushing procedure. The data presented above also demonstrate that acetate pulses introduced at intervals of the order of weeks to months mixed within $5 \mathrm{~m}$ of the permeable wall, as a result of longitudinal dispersion. Furthermore, geochemical changes in the aquifer indicated that this mixing occurred on the scale of the microorganisms and was not merely an artifact of the sampling method.

These findings indicate that a nutrient solution introduced to an aquifer can be delivered, mixed with the contaminated groundwater, to an in situ microbial population by periodically injecting the remedial solution into a permeable wall. A system such as this operates virtually passively; only brief periods of pumping are required at regular intervals. This could result in minimal costs related to maintenance and power requirements, as well as the advantages associated with in situ treatment.

Acknowledgments. This research was funded by the Ontario Ministry of Environment and Energy. Additional support from the University Consortium Solvents-in-Groundwater Research Program is also gratefully acknowledged. Sponsors of the program have included
The Boeing Company, Ciba-Geigy, Dow Chemical, Eastman Kodak, General Electric, Mitretek Systems, Motorola, PPG Industries, United Technologies Corporation, the Natural Sciences and Engineering Research Council of Canada, and the Ontario Research University Fund.

\section{References}

Alyamani, M. S., and Z. Sen, Determination of hydraulic conductivity from complete grain size distribution curves, Ground Water, 31(4), 551-555, 1993.

Ball, W. P., C. H. Buehler, T. C. Harmon, D. M. Mackay, and P. V. Roberts, Characterization of a sandy aquifer material at the grain scale, J. Contam. Hydrol., 5, 253-295, 1990.

Bear, J., On the tensor form of dispersion in porous media, J. Geophys. Res., 66(4), 1185-1197, 1961.

Devlin, J. F., Enhanced in situ biodegradation of carbon tetrachloride and trichloroethene using a permeable wall injection system, Ph.D. dissertation, 633 pp., Dep. of Earth Sci., Univ. of Waterloo, Waterloo, Ont., Canada, 1994a.

Devlin, J. F., A simple and powerful method of parameter estimation using simplex optimization, Ground Water, 32(2), 323-327, 1994b.

Devlin, J. F., and J. F. Barker, A semipassive nutrient injection scheme for enhanced in situ bioremediation, Ground Water, 32(3), 374-380, 1994.

Driscoll, F. G., Ground Water and Wells, Johnson Div., St. Paul, Minn., 1986.

Egboka, B. C. E., J. A. Cherry, R. N. Farvolden, and E. O. Frind, Migration of contaminants in groundwater at a landfill, 3 , Tritium as an indicator of dispersion and recharge, J. Hydrol., 63, 51-80, 1983.

Franz, T., and N. Guiger, FLOWPATH, A two dimensional horizontal aquifer simulation model, Waterloo Hydrogeol. Software, Waterloo, Ont., Canada, 1990.

Freeze, R. A., and J. A. Cherry, Groundwater, 604 pp., Prentice Hall, Englewood Cliffs, N. J., 1979.

Hunt, B., Dispersive sources in uniform ground-water flow, J. Hydraul. Div. Am. Soc. Civ. Eng., 104(HY1), 75-85, 1978.

Kinzelbach, W., Groundwater Modelling, An Introduction With Sample Programs in BASIC, 333 pp., Dev. Water Sci., vol. 25, Elsevier, New York, 1987.

MacFarlane, D. S., J. A. Cherry, R. W. Gillham, and E. A. Sudicky, Migration of contaminants in groundwater at a landfill: A case study, 1, Groundwater flow and plume delineation, J. Hydrol., 63, 1-29, 1983.

Mackay, D. M., and J. A. Cherry, Groundwater contamination: Pumpand-treat remediation, Environ. Sci. Technol., 23(6), 630-636, 1989.

Mackay, D. M., D. L. Freyberg, P. V. Roberts, and J. A. Cherry, A natural gradient experiment on solute transport in a sand aquifer, 1 , Approach and overview of plume movement, Water Resour. Res., 22(13), 2017-2029, 1986.

Nicholson, R. V., J. A. Cherry, and E. J. Reardon, Migration of contaminants in groundwater at a landfill: A case study, J. Hydrol., $63,131-176,1983$. 
Ogata, A., and R. B. Banks, A solution of the differential equation of longitudinal dispersion in porous media, U.S. Geol. Surv. Prof. Pap., 411- $A, 1961$.

Perry, R. H., and D. W. Green (Eds.), Perry's Chemical Engineers' Handbook, 6th ed., McGraw-Hill, New York, 1984.

Roberts, P. V., G. D. Hopkins, D. M. Mackay, and L. Semprini, A field evaluation of in-situ biodegradation of chlorinated ethenes, 1 , Methodology and field site characterization, Ground Water, 28(4), 591604, 1990.

Sudicky, E. A., and J. A. Cherry, Field observations of tracer dispersion under natural flow conditions in an unconfined sandy aquifer, Water Pollut. Res. J. Can., 14, 1-16, 1979.
Sudicky, E. A., J. A. Cherry, and E. O. Frind, Migration of contaminants in ground water at a landfill: A case study, 4, A natural gradient dispersion test, J. Hydrol., 63, 81-108, 1983.

J. F. Barker and J. F. Devlin, Department of Earth Sciences, B. F. G. Building, University of Waterloo, Waterloo, Ontario, Canada N2L 3G1. (e-mail: jfdevlin@sciborg.uwaterloo.ca)

(Received December 21, 1995; revised April 8, 1996; accepted April 9, 1996.) 